\title{
Harnessing repetitive behaviours to engage attention and learning in a novel therapy for autism: an exploratory analysis
}

\section{Grace Megumi Chen ${ }^{1 \dagger}$, Keith Jonathon Yoder ${ }^{2 \dagger}$, Barbara Lynn Ganzel ${ }^{3}$, Matthew S. Goodwin ${ }^{4}$ and Matthew Kenneth Belmonte ${ }^{5,6,7 *}$}

${ }^{1}$ Developmental Disabilities Clinic, Yale Child Study Center, New Haven, CT, USA

2 Division of the Social Sciences, The University of Chicago, Chicago, IL, USA

${ }^{3}$ Department of Human Development, Cornell University, Ithaca, NY, USA

${ }^{4}$ Department of Health Sciences, Bouvé College of Health Science and College of Computer and Information Science, Northeastern University, Boston, MA, USA

${ }^{5}$ The Groden Center, Providence, RI, USA

${ }^{6}$ Center for the Study of Human Development, Brown University, Providence, RI, USA

7 National Brain Research Centre, Manesar, Haryana, India

\section{Edited by:}

Ying Guo, The Ohio State University, USA

\section{Reviewed by:}

Thomas Schanding, University of Houston, USA

Norzarina Mohd-Zaharim, Universiti

Sains Malaysia, Malaysia

\section{*Correspondence:}

Matthew Kenneth Belmonte, National

Brain Research Centre, $\mathrm{NH}-8$,

नैनवाल मोड़, मानेसर 122 050, India.

e-mail: belmonte@mit.edu

${ }^{+}$Grace Megumi Chen and Keith Jonathon Yoder have contributed equally to this work.
Rigorous, quantitative examination of therapeutic techniques anecdotally reported to have been successful in people with autism who lack communicative speech will help guide basic science toward a more complete characterisation of the cognitive profile in this underserved subpopulation, and show the extent to which theories and results developed with the high-functioning subpopulation may apply. This study examines a novel therapy, the "Rapid Prompting Method" (RPM). RPM is a parent-developed communicative and educational therapy for persons with autism who do not speak or who have difficulty using speech communicatively. The technique aims to develop a means of interactive learning by pointing amongst multiple-choice options presented at different locations in space, with the aid of sensory "prompts" which evoke a response without cueing any specific response option. The prompts are meant to draw and to maintain attention to the communicative task making the communicative and educational content coincident with the most physically salient, attention-capturing stimulus - and to extinguish the sensory-motor preoccupations with which the prompts compete. Video-recorded RPM sessions with nine autistic children ages 8-14 years who lacked functional communicative speech were coded for behaviours of interest. An analysis controlled for age indicates that exposure to the claimed therapy appears to support a decrease in repetitive behaviours and an increase in the number of multiple-choice response options without any decrease in successful responding. Direct gaze is not related to successful responding, suggesting that direct gaze might not be any advantage for this population and need not in all cases be a precondition to communication therapies.

Keywords: autism, non-verbal, communication, repetitive behaviours, attention, gaze, eye contact, pointing

\section{INTRODUCTION}

Autistic behaviour and cognition in many ways centre not so much on the presence or absence of specific cognitive abilities, but on how efficiently, rapidly, and flexibly these abilities can be orchestrated and combined in the service of changing cognitive demands (Belmonte et al., 2004a). Intact or superior perceptual or cognitive capacities may seem impaired because they are not rapidly deployed or flexibly combined with other skills. This lack of cognitive integration may relate to a similar lack of integration at a neural level, in which activity-dependent development of long-range connections between brain regions may become impeded (Belmonte et al., 2004a) or in general perturbed (Müller et al., 2011), producing a brain that operates more as a collection of autonomous subprocessors than a coordinated system under top-down direction from a central executive (Belmonte et al., 2010), in which only one process at a time can have access to that central executive, and in which, therefore, attention and conscious processing are captured exclusively by whichever exogenous stimulus or endogenous process is the most salient, and competing processes or stimuli are extinguished in a "winner-takes-all" mode of processing (Bonneh et al., 2008). This neural and cognitive disconnectivity manifests at a perceptual level as autistic superiorities at - and preoccupations with - sensory stimuli of low construal that do not demand integration across multiple perceptual channels (Bertone et al., 2005; Bonneh et al., 2008; Saron et al., 2009; Belmonte et al., 2010), broad areas of space, or multiple sensory modalities (Allen and Courchesne, 2001), at a sensory-motor level as an inability to combine multiple perceptual modalities to inform motor learning (Haswell et al., 2009), at an attentional level as difficulty in shifting or distributing attention between sensory modalities, sensory attributes, or points in space (Belmonte, 2000; Allen and Courchesne, 2001; Belmonte and 
Yurgelun-Todd, 2003), at a cognitive-affective level as an inability to connect motivations with congruent actions simultaneously (Greenspan, 2001), and at a social level as an inability to connect one's own egocentric perspective with the simultaneously, allocentrically represented perspective of one or more social partners (Frith and de Vignemont, 2005).

Physiological and behavioural results supporting this disconnectivity paradigm stem from study of the "high-functioning" autistic subpopulation - those people who are readily able to act on verbal instructions, to keep still during fMRI or EEG measurements, and in general to cooperate with highly prescribed experimental settings. It is possible to conjecture how such neural and cognitive disconnection might extrapolate to more severe impairments outside the "high-functioning" subpopulation: impairments in maintaining a thought simultaneously with its expression in words, the meaning of a word simultaneously with the phonetic sequence and motor plan for its spoken articulation, a salient exogenous percept simultaneously with an endogenous concept, or even an auditory event simultaneously with a visual stimulus.

The key limitation may be that of simultaneity: a person with autism might represent action or motivation, egocentrism or allocentrism, thought or syntax, external perceptual or internal mental events, and sights or sounds - just not at the same time (Bonneh et al., 2008). One possible workaround, then, would involve removing the demand for simultaneity: what if the acts of knowing and imagining, self-representation and other-representation, thinking and phrasing, perceiving and conceiving, seeing and hearing did not have to occur at the same time? In other words, what if communication could take place asynchronously?

Typed text, unlike conversational speech, is an asynchronous communication medium: there is no demand to time utterances to maintain the flow of conversation, no demand for precise temporal sequencing of movements of the throat, tongue, and lips, and no demand to perceive the spoken word in real-time. The partially composed text itself serves as an external memory; thus there is less demand to hold in mind the expression of a thought at the same time as one retains the thought itself. One can leave off in the middle of a word, interrupt to perform a repetitive behaviour, then resume. One can attend to the text and to other stimuli in turns. Thus the narrative structuring inherent in this textual medium can in some measure substitute for the lack of connectivity in the autistic brain. This asynchronous, "offline" form of communication may be more accessible than spoken language for some individuals with autism because the rapidly sequenced and timed mode of vocal production may demand a greater degree of cognitive control than the person with autism can provide (Forsey et al., 1996).

Social communication especially depends on this connectivitydependent, integrative, simultaneous processing, encompassing non-verbal joint attention behaviours that function either to monitor and to respond to a social partner's solicitation of attention, or to solicit the attention of a social partner (Mundy et al., 2003). Such joint attention behaviours allow individuals to share awareness or experience of an object or event (Baron-Cohen, 1989) by discriminating specific objects of social reference. Joint attention behaviours also allow caregivers to follow a child's attention and to impart new information at moments when the child's interest and attention are sufficiently engaged for learning to occur (Tomasello and Farrar, 1986).

Thus, joint attention serves as a foundation for cognitive, social, and language development (Bruner, 1975; Newson and Newson, 1975; Bakeman and Adamson, 1984; Charman, 2003; Mundy and Sigman, 2006; Nathan et al., 2007). Unsurprisingly then, emerging joint attention ability predicts later language ability (Mundy et al., 1990, 2007; Charman, 2003; Toth et al., 2006; Watt et al., 2006; Whalen et al., 2006; Smith et al., 2007; Kasari et al., 2008; Siller and Sigman, 2008), and impairments in joint attention behaviours are amongst the earliest and most predictive indicators of autism (Charman, 2000).

The "Rapid Prompting Method" (RPM), described in two manuals (Iversen, 2007; Mukhopadhyay, 2008) and web sites ${ }^{1}$ and taking inspiration from the Communication DEALL ${ }^{2}$ early intervention programme (Karanth et al., 2010), is a parent-developed educational therapy for persons with autism who do not speak or who have difficulty using speech communicatively. RPM exploits and develops a rhythmic mode of responding in which the disconnection amongst cognitive goal, affective motive, motor plan, and action becomes less significant because the motor action already is programmed as part of an ongoing rhythm of movements. Such an action need not be explicitly initiated, but rather only updated and specified as to its particular target. The more automatic an action, the less the load on cognitive control mechanisms (Chein and Schneider, 2005) - access to which is already compromised in autism (Belmonte et al., 2010). So RPM's rhythmic prompting can be thought of as an exogenous supplement for endogenous mechanisms of cognitive control that support learning. Similar approaches of rhythmic prompting have shown efficacy in neurodegenerative disorders in which motor initiation is compromised (Arias and Cudeiro, 2008).

Similar to the Picture Exchange Communication System (PECS), RPM demands selection from a limited repertoire of choices, and visual tools are used to teach communication (Frost and Bondy, 1994; Mirenda, 2001). These tools include books, letter boards, or stencils, and the teacher's drawings or writings. RPM begins by developing a simple two-alternative forced choice behaviour: the teacher poses a simple question with a predictable answer, in which the two response alternatives are semantically distant from each other, such as "Is the sky red or blue?" The responses "red" and "blue" then are written and placed at a large spatial distance from each other, one in each hemifield. Attention is captured and directed toward the choices by highly salient sensory prompts, which compete with sensory preoccupations and repetitive behaviours, extinguishing them.

Repetitive behaviours can be either calming or arousing (Mukhopadhyay, 2008), working with or against the communicative task. Arousing behaviours are active and attentive, and can commandeer all of a learner's limited capacity for cognitive control; calming behaviours do not demand cognitive control and do not interfere with attention to the tasks of learning and

\footnotetext{
${ }^{1}$ www.halo-soma.org, www.StrangeSon.com

2 www.CommunicationDEALL.org
} 
communication. (Calming repetitive behaviours occur in nonautistic people, too; they are called fidgets.) The RPM teacher's job is to keep calming behaviours from becoming elaborated into arousing behaviours, and to divert attention from arousing behaviours by issuing prompts that compete with them and extinguish them. The pace of prompting is determined by how much the teacher's prompting must compete with the learner's own repetitive behaviours (Iversen, 2007).

Different prompts may work best for different individual learners who respond preferentially to stimuli in one or another sensory modality, or in peripersonal versus distal space. Tearing a piece of paper into two separate response options provides auditory and visual prompting. Shaking of a piece of paper provides visual prompting. Placing a stylus or pencil into the learner's pointing hand provides tactile prompting; the removal of the stylus when a response is made then completes the rhythm of a motor give-andtake intended to scaffold communicative give-and-take. Similarly, a rhythmic, singsong voice with a measured cadence provides auditory prompting in which salient low-level prosodic and phonetic aspects of the sound capture attention, so that the speech stimulus can gain access to semantic processing and "sink in." RPM is about shaping higher-level cognitive rhythms by taking advantage of the autistic learner's tendency to be captured attentionally by low-level sensory and perceptual rhythms. Thus in a sense RPM harnesses repetitive behaviours - or the sensory preoccupations that drive and develop them (Boyd et al., 2010) - to direct attention toward communicative, educational stimuli.

This ability to work with instead of against an autistic, detailoriented, low-construal attentional style is RPM's key innovation: to make the educational and communicative content coincident with the salient, attention-capturing stimulus. This aligning of educational content with the object of a student's attention and motivation is what any teacher usually accomplishes, intuitively, via voice and gaze and gesture: the difference is that, in the case of a student with autism, the attention-capturing stimulus provided by the teacher is a physically salient stimulus rather than one of these more conventional, socially salient stimuli.

RPM therapy sessions follow a "teach-ask" format somewhat similar to discrete trial learning in that the teacher will present a short module, then ask the learner a question about what was previously taught (Mukhopadhyay, 2008). Like discrete trial learning, RPM applies trials in an errorless-learning format, in which the learner is guided to the correct response if they do not produce it on their own. Rather than pressing the learner to provide an immediate response, the teacher waits for the learner, issuing prompts as a means of encouragement. If the learner does not provide a correct response, the teacher does not give negative feedback (i.e., tell the learner "no, that is incorrect"); rather, the teacher will re-state the question or present the question in a different manner (e.g., instead of speaking the question, the teacher may try to engage the learner by writing out the question).

Also similar to discrete trial learning, task complexity in RPM is gradually increased as the therapy progresses. In discrete trial learning this titration is guided by a quantitative criterion for performance, whereas in RPM the trigger is more subjective and guided by the teacher's impression of the learner's level of mastery. Once the learner has become comfortable and practised with two-alternative forced choice, the number of choices presented can be titrated up and the semantic distance between choices titrated down. Similarly, when the learner has become comfortable selecting one amongst a field of choices, the task of spelling out the choice's name by sequential pointing can be appended to the selection task: here again, choice complexity is titrated, beginning with five-character subsets of the Roman alphabet, and ending with the full 26-option slate. Communication then progresses from predictable, single-word answers, e.g., filling blanks in sentences, to answers that admit more than one appropriate choice. Discourses evolve from concrete, factual statements to statements of personal preference or opinion.

Crucially, prompting is not the same as direction. Prompts serve to redirect the learner's attention to the task of responding (e.g., "Show me the answer"), but do not cue any specific response. Prompting is provided not to direct a learner to a correct answer, but rather to elicit a response - any response, whether correct or incorrect. The teacher will often speak in a tone that reflects confidence in the learner's ability - a key motivational factor. Even in the errorless-learning format, learners are directed to one response or another not physically, but with verbal prompts instructing movements, e.g., "Lift your elbows, a bit more to the right," or by the teacher's modeling a selection of one or the other response. Joints or hands or fingers are never held or moved by the teacher. RPM practitioners are careful to point out that if the learning of self-directed pointing is hurried, the learner can become vulnerable to unconscious influence by the teacher (Mukhopadhyay, 2008). This liability was of course the undoing of Facilitated Communication (Mostert, 2001), and the absence of any guiding touch is a crucial distinction inherent to the practice of RPM.

The RPM teacher calibrates the pace of prompting to the learner's sense of timing and ability to respond. Thus, a synchrony between the learner and a familiar teacher develops over time; unlike other communication interventions, the emphasis on the rhythmicity and frequency of prompts acts to build a rapport with the learner (Iversen, 2007). In this regard, the constancy of a familiar teacher may be an affective analogue to the sensory constancy of rhythmic prompting, deep pressure, or any of the many other sensory approaches to anxiety relief for people with autism.

RPM has accumulated anecdotal support but has not yet undergone controlled evaluation. The teaching material (i.e., arithmetic, reading comprehension, geography) can come from general educational curricula; however, the method of teaching must be individualised to each child's initial abilities (Karanth et al., 2010). During the initial sessions, the therapist aims to assess the child's strengths in terms of preferred channels of sensory perception. Some children may preferentially respond better to vocal stimulation, whereas other auditory, visual, and/or tactile stimulation may work better for others - the underlying notion being that if people with autism have difficulty integrating multiple perceptual channels, they will tend to adapt by becoming specialists in only one sensory modality (Bonneh et al., 2008). Thus, one of the initial steps in providing RPM therapy is to determine how to individualise the therapy, just as in discrete trial learning. The teacher may rely on observations of the types of sensory preoccupations and repetitive behaviours exhibited 
and how the learner responds to various prompting modalities (auditory, visual, tactile) to determine how to individualise the therapy. Lessons are individualised not only by centring on the learner's academic interests, but also by centring on - and competing with and extinguishing - the learner's sensory interests (Mukhopadhyay, 2008).

Such sensory interests often manifest as stereotypies, and children with autism who lack communicative speech exhibit more repetitive and stereotypic behaviours (RSBs), across a variety of interpersonal settings (Dadds et al., 1988). One explanation for this association is that these children lack communicative speech because their RSBs interfere with learning social and communicative behaviour. Alternatively, RSBs may emerge to fill a void where these more complex social and communicative behaviours have been disrupted (or perhaps a self-reinforcing mix of both these causal directions). In the early days - and the dark ages of autism therapy, scientists and clinicians tended to accept the first of these causal directions and attempted to suppress RSBs, often using painful and other aversive reinforcers (Risley, 1968). The converse model is one in which repetitive behaviours emerge when social and communicative behaviours are disrupted, and subside on their own when social function and communication are enabled (see Baer et al., 1967; Goetz et al., 1975; Repp et al., 1976; Luiselli et al., 1985).

This latter view is central to RPM. Difficult behaviours are taken as opportunities for communicating, thinking about consequences, and learning, again within the RPM paradigm of choice amongst dual or in general multiple options, e.g., "What do you think happens when you pull my hair? Do I get HURT, or does it RAIN?" (Mukhopadhyay, 2008). Combination of this studentcentred subject matter with the errorless-learning approach means that even if the student is preoccupied with an intrusive behaviour, that behaviour is redirected toward the learning task by the teacher's errorless-learning direction. Spatial placement of the response options, too, is individualised to the learner's motor abilities - for instance those with good control over shoulder movements but less control over hand movements would need the choices placed more distally.

Communication strategies that capture attention via low-level sensory salience rather than via complex integrative processing, that minimise integration and simultaneity of cognitive processes, and that maximise asynchronous and piecemeal, sequential processing, would minimise dependence on centralised cognitive control, and may thus enable the expression of cognitive capacities hitherto unmanifest. If such were the case, exposure to RPM could be expected to decrease repetitive behaviours as its prompts would compete with and displace these, and also perhaps to increase behaviours associated with joint attention as learners' attention would be captured by the teacher's prompts and directed toward the choice objects.

Joint attention is frequently operationalised with reference to typically developing individuals as the frequency with which a child triadically looks back and forth between a task at hand and the person with whom he or she is interacting (Lord et al., 2000; Gernsbacher et al., 2008). Because impairments in joint attention are thought to be a downstream behavioural manifestation of early brain neuropathology (Charman, 2003), absence of gaze-following behaviour has been used to detect and to diagnose autism (Baron-Cohen et al., 1996).

More recently, gaze behaviour has been used to provide an overt means of assessing joint attention, and eliciting appropriate gaze behaviour has become a target in itself of some therapeutic interventions for children with autism that strive to use nonverbal social-communicative skills to enhance language and social development (Rogers and Lewis, 1989; Whalen and Schreibman, 2003; Charman, 2003). The efficacy of such therapies has been proven - but the question remains, to what degree does learning in autism depend essentially on overt indices of joint attention that are drawn from the typical population?

As a first step in assessing RPM's claim of therapeutic effect, therefore, we hypothesised that exposure to RPM therapy across several sessions would (1) increase gaze indicative of joint attention and (2) decrease repetitive behaviours, resulting in an inverse relationship between joint attention and repetitive behaviours; and that (3) prompting also would be associated with decreases in repetitive behaviours. In addition we predicted that, in accordance with RPM's claimed strategy of titrating up choice complexity as the learner becomes practised, (4) analysis across sessions would show an increase in choice complexity with no decrement in the accuracy of the chosen responses. As an exploratory analysis, we also were interested in (5) the nature of the prompts associated with accurate responding and with extinguishing of repetitive behaviours: what sensory modality or modalities of prompting, what timings, and what proximities of such prompts are most closely associated with these learning-related behaviours?

We address these questions via detailed behavioural analysis of video-recorded therapy sessions from a small sample comprising nine individual cases. Video recordings have been used previously to discern the developmental stage at which early characteristic autistic behaviours begin to emerge in individuals, and to determine which behaviours have the greatest predictive value. The use of recorded material of older, non-verbal children with autism in these studies serves as precedent for our use of video data in the current study (e.g., Osterling and Dawson, 1994; Baranek, 1999; Palomo et al., 2006). Such video coding of responsive and initiative joint attention has also been applied to demonstrate correlation between joint attention behaviours measured in a structured interaction and in a naturalistic context (Roos et al., 2008). These results provide empirical support for the use of video records as a viable means of assessing joint attention.

We defer, for the moment, the crucial question of whether the communications produced during RPM therapy are genuine. Our aim in this preliminary, case-based study is only to test for behavioural effects that would be consistent with RPM's claimed strategy and mechanism: is there any plausibility to RPM's anecdotal reports? If the measured effects are consistent with the claimed mechanisms, the question of whether, for whom, and under what circumstances RPM produces valid communications would be the proper subject of a future, separate, larger study.

\section{MATERIALS AND METHODS SUBJECTS}

The study was reviewed and approved by the Cornell University Institutional Review Board. Video-recorded sessions of nine 
sequentially enrolled subjects (seven boys, two girls; mean age 10.7 years SD 2.42, age range 8-14 years) undergoing RPM therapy were coded, with special attention to identifying behaviours that were likely to impact learning in this non-speaking autistic sample. Video data for each subject comprised several therapy sessions, each $60 \mathrm{~min}$ long. All subjects had the same therapist who is the developer of RPM, and who possesses a master's-level background in science education as well as a decade and a half of special education experience, beginning as a parent volunteer in India, and continuing as the founder of her own clinic in the United States. Subjects received one-to-one RPM therapy in a classroom-like setting at this clinic, Helping Autism through Learning and Outreach, in Austin, TX, USA. Because the RPM therapy was formatted as "camp" stays, subjects experienced varying numbers of sessions depending on how long they were able to visit the clinic site; four subjects each had four sessions, one child had five sessions, and four subjects each had eight sessions. Subject information is presented in Table 1.

Subjects were referred based on a previous clinical diagnosis of autism, and lack of flexible, communicative speech. For each subject, parents filled an intake form indicating the child's previous and current therapy, expressive language ability, primary repetitive or autistic behaviours, strengths, and any work the parents did with their child at home. Three subjects $(\# 3, \# 4, \# 7)$ had no speech at all, three (\#2, \#5,\#6) had only single words, two $(\# 1, \# 8)$ had only two-word phrases, and one (\#9) had words and phrases with a few very scripted complete sentences. Some subjects had echolalic speech in addition to these very limited degrees of communicative speech. All subjects were thus highly impaired at functional spoken communication.

Subject 1 (14 years 1 month) had a history of receiving Applied Behavioural Analysis (ABA) and vitamin therapy. Though not conversational, she was able to use single words and short phrases (e.g., "Hey, Mom!") to communicate her wants and needs. She exhibited delayed echolalia, repeating lines from films or television programmes. Occasionally, she laughed and smiled inappropriately. Her primary repetitive behaviours included stereotypic vocalisations, frequent hand flapping, and tugging on clothes. Her parents reported drawing, skiing, ice skating, riding horses and communicating needs and wants as strengths.
Subject 2 ( 8 years 3 months) had a history of ABA in an Incidental Teaching format, and occupational therapy (OT). His expressive language consisted almost exclusively of delayed echolalia, often including songs (e.g., "Twinkle, Twinkle Little Star”), but did include single words spoken communicatively. His speech was difficult to understand at first because of poor enunciation. Though he would, on rare occasion, clap or wring his hands, Subject 2 had few repetitive, physical behaviours. He tended to try to escape from situations in which he felt uncomfortable, e.g., by crawling under a table. His memory was described as "almost photographic," and he could recite hours of dialogue from a video seen only once months ago.

Subject 3 ( 10 years 3 months) had had no prior treatments or therapy history. Though he lacked speech entirely, he would squeeze someone's hand or pinch if he were not feeling well. His repetitive behaviours included chewing objects, holding a string in tension between his hand and his teeth, mouthing objects, and obsessive play with a ball. Additionally, when seated at a table, he would alternate between stamping and rocking in his chair.

Subject 4 ( 11 years 4 months) had a therapy history of ABA, OT, and horseback riding. He had no speech. Grunting was his primary stereotypic vocalisation. His repetitive behaviours revolved around strings, which he would dangle or twirl in front of his eyes or pull with his thumbs and forefingers. He was attending a full day school programme and was capable of self-care and chores. His strengths were his memory and his problem-solving skills. At home, his parents worked with him on oral motor reinforcement and ABA in an Incidental Teaching format.

Subject 5 ( 14 years 2 months) had a history of OT and PECS. His expressive language was limited to a few single words (e.g., "Hey," "Mama"). His repetitive behaviours involved flapping ribbons, shoelaces, or his fingers in front of his face, as well as rocking in his chair and stereotypic vocalisations. When distressed, he would imitate a siren. At home, he used PECS to make requests and was able to dress and groom himself, to tie his shoes and to perform some household chores (e.g., laundry).

Subject 6 (8 years 10 months) had a history of ABA, Relationship Development Intervention (RDI), and speech OT. Though his speech was limited to single words, he was able to spell words aloud. His repetitive behaviour consisted mostly of stereotypic vocalisations, particularly high-pitched squealing, and he would

Table 1 | Subject information.

\begin{tabular}{lllll}
\hline & Gender & Age & CARS estimate* & Sessions coded \\
\hline Subject 1 & F & 14 years 1 month & 45 & $1,2,4,8$ \\
Subject 2 & M & 8 years 3 months & 45.5 & $1,2,4,8$ \\
Subject 3 & M & 10 years 3 months & 49.5 & $1,2,4$ \\
Subject 4 & M & 11 years 4 months & 46 & $1,2,4$ \\
Subject 5 & M & 14 years 2 months & 46 & $1,2,4$ \\
Subject 6 & M & 8 years 10 months & $1,2,4,8$ \\
Subject 7 & M & 13 years 10 months & 46 & $1,2,4,8$ \\
Subject 8 & F & 9 years 11 months & 50 & $1,2,4$ \\
Subject 9 & M & 13 years 3 months & 49 & $1,2,4$ \\
\hline
\end{tabular}

${ }^{*}$ CARS estimates are defined as the minimum possible CARS score based on items that could be scored during sessions. 
seek sensory stimulation by burying his head into the therapist's or his parents' shoulders. He often expressed inappropriate delight and laughter. His primary strength was his memory.

Subject 7 ( 13 years 10 months) had a history of ABA and some PECS. He lacked speech entirely and attempts to use PECS were not very successful. At intake, he was learning American Sign Language. His repetitive behaviours involved spitting, finger flicking, stereotypic vocalisations, biting his arms, and slapping himself on the mouth.

Subject 8 (9 years 11 months) had a history of speech therapy and OT. She had a very large vocabulary, which she used to communicate. However, her speech was limited to very short phrases, mostly one-word utterances to express desires or "Yes" and "No" in response to simple questions. She also demonstrated delayed echolalia - singing children's songs. Her primary stereotypic behaviour was picking at pieces of tape placed on her arm.

Subject 9 ( 13 years 3 months) had a history of ABA, homebased public school services, nutritional supplements, and speech therapy. His speech was limited to scripted verbalisations which included some complete sentences - for example "I want ___," "I don't like __.." His repetitive behaviours included tapping surfaces, grunting, and other vocalisations, and pacing. One year prior to beginning RPM, he had become aggressive at school, but after switching to home schooling he was calm and gentle.

In addition to receiving a clinical diagnosis of autism prior to the RPM intervention, each subject amply demonstrated satisfaction of DSM-IV-TR criteria for autism. Behavioural severity was quantified using the Childhood Autism Rating Scale (CARS; Schopler et al., 1980), a diagnostic assessment method used to differentiate children with autism from those with other developmental delays using scoring criteria (non-autistic to severely autistic) across 15 categories of behaviour. These 15 items together cover social responsiveness, speech, non-verbal communication, emotional reciprocity, imitation, resistance to change, motor skills and stereotypies, attention and perceptual integration, sensory sensitivities, fear and anxiety, hyperactivity, and intellectual functioning. The CARS thus is a practical and brief measure that nonetheless encompasses both the social-communicative and the behavioural flexibility aspects of autism's diagnostic triad. Because families who had travelled to the clinic could not be available for very lengthy interviews and observation sessions separate from the therapeutic sessions, the CARS was the most practical measure for verifying autism diagnoses. In addition, it must be noted that these cases of severe autism without communicative speech can be much less equivocal in terms of diagnosis than high-functioning autism or Asperger syndrome, and therefore a brief measure such as the CARS can suffice to verify prior clinical diagnoses in such cases.

CARS scores were conservatively estimated: each item was scored as one (normal) unless a specific behaviour indicated otherwise. These conservative, lower-bound estimates of CARS scores were produced by two raters (GMC and KJY) trained on the CARS using the Western Psychological Services demonstration video. Training materials and practice ratings were discussed with a supervisor $(\mathrm{MKB})$ with 18 years of experience recruiting and characterising individuals with autism. Inter-rater agreement was at least 0.80 for each CARS score. Each subject's conservative estimate met the CARS threshold of 30 (Table 1). In particular, each case justified a score of at least three (moderately abnormal) for item 11 (Verbal Communication) and 4 (severely abnormal) for item 15 (General Impression). Item 14 (Level and Consistency of Intellectual Response) was conservatively coded as one (normal) in all cases.

\section{CODING}

An original coding scheme was developed to assess: (1) choice complexity; and (2) occurrence and relative timing of the subject's behaviour (including learning-related behaviours), and the therapist's requests and prompts. Subject behaviours included responses to requests, appropriate/successful response, attention, non-task activity, and autistic behaviours. The coding scheme drew on items from the Early Social Communication Scales (Mundy et al., 2003), the Autism Diagnostic Interview - Revised (Lord et al., 2000) and the Informative Pointing Method manual (Iversen, 2007). The coding scheme also included learning-related behaviours based on the targeted behavioural objectives of the RPM intervention, which attempts to develop communication by a strategy of prompted pointing (Mukhopadhyay, 2008). The three general categories in the coding scheme were learning-related behaviours (Table 2), child's autistic behaviours (Table 3), and therapist's request and prompts (Table 4).

The middle $10 \mathrm{~min}$ (25-35 min into the session) of the first, second, fourth, and (if available) the eighth therapy sessions were coded. In two instances where the subject was not within the frame of the video during this middle interval, an earlier interval (15-25 min) was used. The middle segments of the sessions were selected so as to eliminate possible behavioural confounds

Table 2 | Learning-related behaviours.

\begin{tabular}{lll}
\hline Behaviour & Example & Scoring procedure \\
\hline $\begin{array}{l}\text { Engaged attention } \\
(0.45 \pm 0.10,92 \%)\end{array}$ & $\begin{array}{l}\text { Subject looks from object in target area (i.e., piece of } \\
\text { paper) to therapist, as the therapist explains something. }\end{array}$ & $\begin{array}{l}\text { Continuous: stop when subject physically or verbally begins to } \\
\text { respond. Begin immediately after a response (or continuous } \\
\text { series of responses) is given. }\end{array}$ \\
$\begin{array}{lll}\text { Non-engaged attention } \\
(0.47 \pm 0.19,90 \%)\end{array}$ & $\begin{array}{l}\text { Subject glances at walls while therapist is pointing at an } \\
\text { object on the table. }\end{array}$ & $\begin{array}{l}\text { Continuous: stop when subject physically or verbally begins to } \\
\text { respond. Begin immediately after a response (or continuous } \\
\text { series of responses) is given. }\end{array}$
\end{tabular}

Cohen's kappa and percent agreement for each variable are given in parentheses. 
Table 3 | Autism behaviours.

\begin{tabular}{|c|c|c|c|}
\hline Behaviour & Description & Example & Scoring procedure \\
\hline $\begin{array}{l}\text { Aggression to therapist } \\
(0.48 \pm 0.07,98 \%)\end{array}$ & $\begin{array}{l}\text { Any aggressive actions directed } \\
\text { toward the therapist. }\end{array}$ & $\begin{array}{l}\text { Hitting, kicking, biting, etc. - } \\
\text { antisocial behaviours directed } \\
\text { toward the therapist. }\end{array}$ & $\begin{array}{l}\text { Begin coding at onset of aggressive behav- } \\
\text { iour; stop coding when the behaviour ends and } \\
\text { action stops. }\end{array}$ \\
\hline $\begin{array}{l}\text { Self-injurious behaviour } \\
(0.38 \pm 0.19,94 \%)\end{array}$ & $\begin{array}{l}\text { Any aggressive actions or } \\
\text { behaviours directed toward self. }\end{array}$ & $\begin{array}{l}\text { Hitting, scratching, biting, etc. - } \\
\text { behaviours directed toward self. }\end{array}$ & $\begin{array}{l}\text { Begin coding at onset of self-injurious beha- } \\
\text { viour, stop coding when the behaviour ends. }\end{array}$ \\
\hline $\begin{array}{l}\text { Irrelevant and repetitive } \\
\text { vocalisations } \\
(0.50 \pm 0.23,93 \%)\end{array}$ & $\begin{array}{l}\text { Any vocalisation from the subject } \\
\text { that is not task-relevant or part of an } \\
\text { appropriate vocal response. }\end{array}$ & $\begin{array}{l}\text { Screaming, yelling, inappropriate } \\
\text { laughing, or any other irrelevant } \\
\text { and/or in appropriate vocalisations }\end{array}$ & $\begin{array}{l}\text { Begin coding at the onset of vocalisation, stop } \\
\text { coding once irrelevant vocalisation ends. }\end{array}$ \\
\hline $\begin{array}{l}\text { Repetitive motor } \\
\text { movement } \\
(0.48 \pm 0.11,91 \%)\end{array}$ & $\begin{array}{l}\text { Motor movements that occur at } \\
\text { least three times, plus any } \\
\text { additional occurrences of those } \\
\text { movements. }\end{array}$ & $\begin{array}{l}\text { Flapping of arms, rocking, flicking } \\
\text { fingers, tapping. }\end{array}$ & $\begin{array}{l}\text { Code when movement begins, stop coding } \\
\text { when the movement stops. *If a movement } \\
\text { happens three times in a row in any instance } \\
\text { during the video, other instances of the same } \\
\text { movement still count as repetitive movements } \\
\text { even if they happen only twice. }\end{array}$ \\
\hline $\begin{array}{l}\text { Repetitive object usage } \\
(0.37 \pm 0.12,95 \%)\end{array}$ & $\begin{array}{l}\text { Any seemingly non-communicative, } \\
\text { repetitive physical manipulation of } \\
\text { an object. }\end{array}$ & $\begin{array}{l}\text { Repetitively spinning, tapping, } \\
\text { rolling an object. }\end{array}$ & $\begin{array}{l}\text { Begin coding when action begins, stop coding } \\
\text { when repetitive behaviour ends. }\end{array}$ \\
\hline
\end{tabular}

Cohen's kappa and percent agreement for each variable are given in parentheses.

due to adjusting to the start of a new session and/or fatigue and boredom-related behaviours in the latter half of RPM sessions. Data from the first RPM session provided the ideal baseline - as opposed to the alternative of a pre-RPM measure - because it allowed for controlling any possible confounds associated with the environment in which the subject was assessed.

Clips were coded using VCode video annotation software (Hagedorn et al., 2008) by two coders who were blind to the chronological order of the sessions. (Sessions were randomised and assigned a false chronological order.) Each clip was coded in continuous 5-s intervals, such that coders focused on 5-s segments at a time, rather than a 10 -min session in its entirety. Variables were coded in four rounds: the first round coded attention and choice complexity, the second coded types of stimuli and subject's behaviours, the third coded therapist requests and prompts, and the fourth coded types of response. A frequency-recording strategy was used to compute rates of incidence of instantaneous, momentary behaviours, and a duration-recording strategy was used to compute time percentages occupied by continuous, temporally extended behaviours. [The fractionation into 5-s intervals was for convenience of coding only; behavioural codings were not quantised in any whole-interval (continuous) or partial-interval (at least once) strategy.]

\section{Inter-rater reliability}

Six of the 31 sessions (i.e., 20\% of the total data analysed) were coded by both coders (again GMC and KJY) and Cohen's kappa scores were calculated. Agreement was at least $90 \%$ for all variables (see Tables 2-4 for specific agreement values). (Kappa values depend on the probability of chance agreement of the rated behaviour, which in turn depends on the frequency of the actual behaviour. Because these behavioural frequencies varied across sessions, and across subjects randomly, the resulting kappa values might not be especially reliable measures of inter-rater reliability. Both the raw percent agreement and the kappa derived from it are therefore reported.)

\section{Attention}

To measure attention, duration and frequency of gaze behaviours were continuously recorded throughout each session and throughout each analysed interval. Throughout the continuous recording, if the subject was looking at either the therapist or an object to which the therapist was attending, attention was coded as "engaged." Brief gaze fixations of the therapist or object lasting less than $2 \mathrm{~s}$ were not counted. If the subject was looking at anything other than the therapist or an object to which the therapist was attending, attention was coded as "non-engaged." Attention was not coded if the subject moved out of the frame or the subject's eyes were obscured (during the 10-min segment, subjects were in frame an average of $8 \mathrm{~min}$ ).

\section{Choice complexity}

For each request presented, there was an associated number of possible answers. A subject could be asked by the therapist to choose among two, three, four, five, or six or more possibilities. Choice complexity was annotated when a subject began a response.

\section{Subject behaviour}

Aggression to therapist, self-injurious behaviour, vocal protest (defined as any vocalisation without evident relevance to the task), repetitive movement, and repetitive object usage were coded. Movements were considered repetitive if they occurred more than three times sequentially. Subject behaviour was coded for duration and time of occurrence. 
Table 4 | Therapist requests and prompts.

\begin{tabular}{ll}
\hline Behaviour & Description \\
\hline Verbal request & Therapist verbally asks the subject to \\
$(0.23 \pm 0.14,91 \%)$ & make a choice: must be in the form of \\
& a question or *implied request.
\end{tabular}

Distal momentary prompt

$(0.28 \pm 0.05,91 \%)$

Proximal momentary

prompt

$(0.37 \pm 0.17,92 \%)$

Distal extended prompt

$(0.37 \pm 0.20,92 \%)$

Proximal extended prompt

$(0.37 \pm 0.24,95 \%)$

Choice complexity

$(0.47 \pm 0.12,97 \%)$
Auditory or visual prompt that follows a

previously given request.

Tactile contact between therapist and subject, following a request.

Therapist moves a material object with the intent of getting the subject's attention.

\section{Example}

"Should the answer be green or blue?"

*For instance, if the only verbal exchange

is "Now, 4 times 7 .. 4 times 7"

(therapist), then mark the first time she

says " 4 times 7" as the verbal request

and the " 4 times 7 " after that as the

verbal prompt.
Therapist asks "Which colour is that?" and/or points to a coloured object.

Gentle prodding of the subject after a verbal/physical request has already been given (pushing a stylus into the subject's hand).

Tearing paper, taping paper, pointing to letter board, loud folding of paper.

\section{Scoring procedure}

Begin coding at the start of the interrogative clause or implied request (i.e., "Show me how to spell 'cat"').

Mark prompt at the beginning of each occurrence.

Mark prompt at the beginning of each occurrence.

Code when movement begins and stop coding when movement ends (i.e., mark in when therapist grabs tape holder, stop after therapist is done taping piece of paper down).

Holding subject's hand while tracing a figure

Therapist presses subject's hand twice to demonstrate "two."

Two possible answers given on two separate scraps of paper

Five choices of letters from a letter board.
Mark code in when contact begins and mark out when contact ceases.

Mark code in when first choice is made (even if this initial choice is incorrect). $\mathrm{EACH}$ verbal request made by the therapist).

Cohen's kappa and percent agreement for each variable are given in parentheses.

\section{Responses}

Responses were coded based on whether the subject exhibited engaged or non-engaged attention prior to providing a response, the modality of response (verbal, or with the use of a stylus, or physical gesture) and whether the response was successful on the first attempt ("originally successful"), unsuccessful, or successful only after the subject was guided to the correct answer in an "errorless-learning" format. For example, if the subject responded correctly the first time, the response was coded as "originally successful." If the subject self-corrected, the first response would be coded as "unsuccessful" and the latter responses would be coded as "successful." Thus, there were 18 possible types of response ( 2 attention $\times 3$ modality $\times 3$ accuracy). Responses were coded when a subject began a response (e.g., at the moment a subject put a stylus to a piece of paper). If a request required a sequence of responses, each response in the sequence was coded individually. For example, if the subject were asked to spell "cat" using a letter board, then at least three responses would be coded - one for the letter $\mathrm{C}$, one for the letter $\mathrm{A}$, and one for the letter $\mathrm{T}$.

It is important to note that a response was "originally successful" only in cases when the subject successfully indicated a response choice that was accepted by the therapist. For instance, if a question were presented in the form "What is two plus two?" the subject would have to indicate "four." The subject could touch a piece of paper on which the therapist had written a four, point to a four on a number board using a stylus, or say the word "four" aloud. If the therapist's intention was unclear or if the request was one that required a subjective response (e.g. "Did that hurt?"), the response, or sequence of responses, to that request was not coded.

\section{Requests}

Verbal requests given by the therapist were also coded. Requests were defined as a direct question ("Is the sky blue or red?") or implied request ("Show me how to spell 'cat"). A verbal request was coded when the therapist began to speak a question or made a request.

\section{Prompts}

Additional interactions between the therapist and the subject were subdivided based on timing and proximity to the subject. Interactions that were transient or nearly instantaneous (e.g., therapist places a stylus in the subject's hand) were coded as "momentary" prompts. To count as a momentary prompt, the interaction needed to occur after a verbal request and before the subject had finished 
responding. Interactions that were ongoing (e.g., therapist shakes the letter board in front of the subject's face) were classified as "extended" prompts. If a prompt involved physical contact with the subject, it was coded as "proximal." Prompts that did not involve physical contact were coded as "distal." Thus, our coding scheme specified four types of prompts: momentary distal, momentary proximal, extended distal, and extended proximal.

\section{STATISTICAL ANALYSIS}

Every variable was normalised by the total time available for coding that variable - for example, "Engaged attention" and "Nonengaged attention" both were divided by the total time during which the subject's gaze direction was visible. Average choice complexity for each session was determined by weighting the number of responses at each level of complexity by that complexity (two times the number of responses that had a choice complexity of two, etc.), then dividing by the total number of responses. Response success rate was calculated by dividing the total number of originally successful responses by the total number of responses in a given session. Finally, the amount of time spent in RSB was calculated by summing the amount of time spent in repetitive movement, or repetitive object usage, and incidence rate of RSB was calculated by summing the number of occurrences of repetitive movement and repetitive object usage. Incidence rates for behaviours of interest were defined as the number of onsets of the behaviour per second. Descriptive statistics for these normalised variables are shown in Table 5.

A two-level analysis, first within and then across subjects, was implemented in a linear mixed-effects statistical model. Within each subject, across each session, the effects of the independent variables (1) session order, (2) percentage of session spent in engaged attention, (3) percentage of session in which the therapist provided prompting, and (4) incidence rate of therapist prompts were computed on the following dependent variables: (1) percentage of session spent in RSB, (2) incidence rate of RSB, (3) average choice complexity, (4) response success rate, and (5) incidence rate of responses. (In addition, these putatively independent variables

Table 5 | Descriptive statistics for normalised variables.

\begin{tabular}{lll}
\hline & Mean & SD \\
\hline Engaged attention & 0.454 & 0.269 \\
Non-engaged attention & 0.564 & 0.269 \\
Aggression to therapist & 0.001 & 0.003 \\
Self-injurious behaviour & 0.007 & 0.032 \\
Irrelevant and repetitive vocalisations & 0.114 & 0.111 \\
Repetitive movement $_{\text {Repetitive object usage }}$ & 0.075 & 0.156 \\
Verbal request $^{\dagger}$ & 0.028 & 0.116 \\
Distal momentary prompt $^{\dagger}$ & 0.035 & 0.012 \\
Proximal momentary prompt $^{\dagger}$ & 0.135 & 0.110 \\
Distal extended prompt $^{\dagger}$ & 0.050 & 0.043 \\
Proximal extended prompt $^{\dagger}$ Choice complexity & 0.535 & 0.308 \\
& 0.018 & 0.028 \\
\end{tabular}

Variables were normalised by amount of available time in which event could occur (see Statistical Analysis for further details).

${ }^{+}$Occurrences per second. were assessed for effects on each other.) To control for age, subjects' ages in months were included as a factor in each model. The significance of each parameter of interest was assessed using a two-tailed test and 22 degrees of freedom. Tail probabilities were corrected by estimating the false discovery rate using a bootstrap method (Storey, 2002). Reported $p$ values are corrected. Statistical calculations were performed in MATLAB ${ }^{\circledR}$ (R2008a, The MathWorks, Natick, MA, USA) and R (2.13.2, R Foundation for Statistical Computing, Vienna, Austria).

\section{RESULTS}

Table 6 shows the regression coefficients for each dependent and independent variable. Table 7 shows the regression coefficients calculated amongst the independent variables related to session order and prompting, and their relationship with overtly engaged attention.

\section{ATTENTION ACROSS SESSIONS}

Session, engaged attention, and therapist prompting were not significant predictors of each other (hypothesis \#1 not confirmed). The percentage of the session in which the subjects' attention was coded as engaged was not significantly related to any of the variables analysed.

\section{REPETITIVE AND STEREOTYPIC BEHAVIOURS}

As the therapy progressed, the incidence rate of RSBs decreased (hypothesis $\# 2$ confirmed, $b=-0.0110, p=0.045$ ) (Figure 1). The percentage of the session during which subjects engaged in RSBs also decreased $(b=-0.023)$, though this relationship did not reach significance $(p=0.129)$. As an incidental result, both percent RSB $(b=-0.389, p=0.002)$ and RSB rate $(b=-0.160$, $p=0.001)$ were inversely related to the percentage of time subjects exhibited engaged behaviour (Figure 2).

After controlling for age, the percent RSB and RSB rate were not significantly predicted by any therapist prompting (hypothesis \#3 not confirmed, $p>0.2$ ).

\section{Subject responses}

As sessions increased, the incidence rate of subject responses increased as well $(b=0.0213, p=0.002)$. The percentage of time spent in engaged attention and the percentage of time during which the therapist provided prompting were not significant predictors of subject response rate $(p>0.8)$. However, the rate at which the therapist provided prompts was a highly significant predictor of subject response rate $(b=0.480, p=0.00004$; Figure 3).

The percentage of responses that were scored as successful was not significantly predicted by session order, therapist prompting, or either measure of RSB. Successful responding was also not related to overtly engaged attention (Figure 4).

Session showed a positive relationship with choice complexity $(b=0.166$; Figure 5), however, this trend did not survive correction for multiple comparisons $(p=0.0697$, hypothesis \#4 suggestive trend but not confirmed). Complexity was not significantly predicted by engaged attention or the percentage of the session in which the therapist provided prompting. The incidence rate of therapist prompts was a significant positive predictor of choice complexity ( $b=3.45, p=0.045$; Figure 6 ). 
Table 6 | Regression coefficients for RSB and responses.

\begin{tabular}{lcccc}
\hline & Session & Engaged attention & Percent prompting & Prompt rate \\
\hline Response rate & $0.0213^{* *}$ & 0.0092 & -38.0 & $0.480^{* *}$ \\
Percent successful & 0.0082 & -0.092 & 97.4 & 0.0796 \\
Percent RSB & -0.023 & $-0.389^{* *}$ & -594 & 0.388 \\
RSB rate & $-0.0110^{*}$ & $-0.160^{* *}$ & 222 & -0.00415 \\
Average complexity & 0.166 & -0.0055 & 469 & $3.45^{*}$ \\
\hline
\end{tabular}

Rates are defined as the number of occurrences per second. Percents are the percentage of the session during which the specified behaviour was occurring. ${ }^{a}$ Percent Successful is defined as the percentage of responses that were coded as successful.

$R S B$, repetitive and stereotypic behaviour; ${ }^{*} p<0.05 ;{ }^{*} p<0.01$; see text for more precise tail probabilities.

Table 7 | Relationships amongst independent variables.

\begin{tabular}{|c|c|c|c|c|}
\hline & Session & Engaged attention & Percent prompting & Prompt rate \\
\hline Session & & -0.289 & -624 & 0.932 \\
\hline Engaged attention & -0.0000504 & & -442 & -0.0685 \\
\hline Prompt rate & 0.00308 & -0.0112 & -170 & \\
\hline
\end{tabular}

Rates are defined as the number of occurrences per second. Percents are the percentage of the session during which the specified behaviour was occurring. $R S B$, repetitive and stereotypic behaviour; * $p<0.05$; see text for more precise tail probabilities.

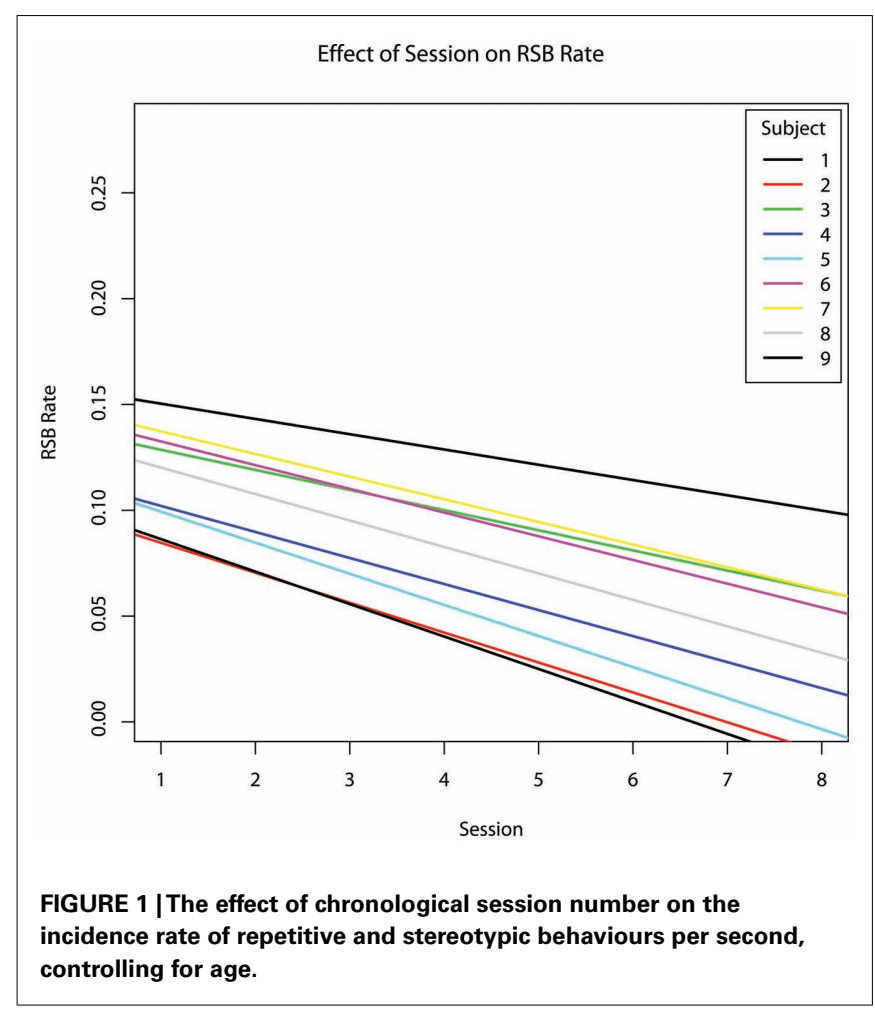

\section{PROMPTING}

As an exploratory analysis, the effects of incidence rate and percent time for both proximal and distal prompt types were examined individually (exploratory hypothesis \#5; Table 8). The percentage of sessions during which subjects exhibited RSBs was not

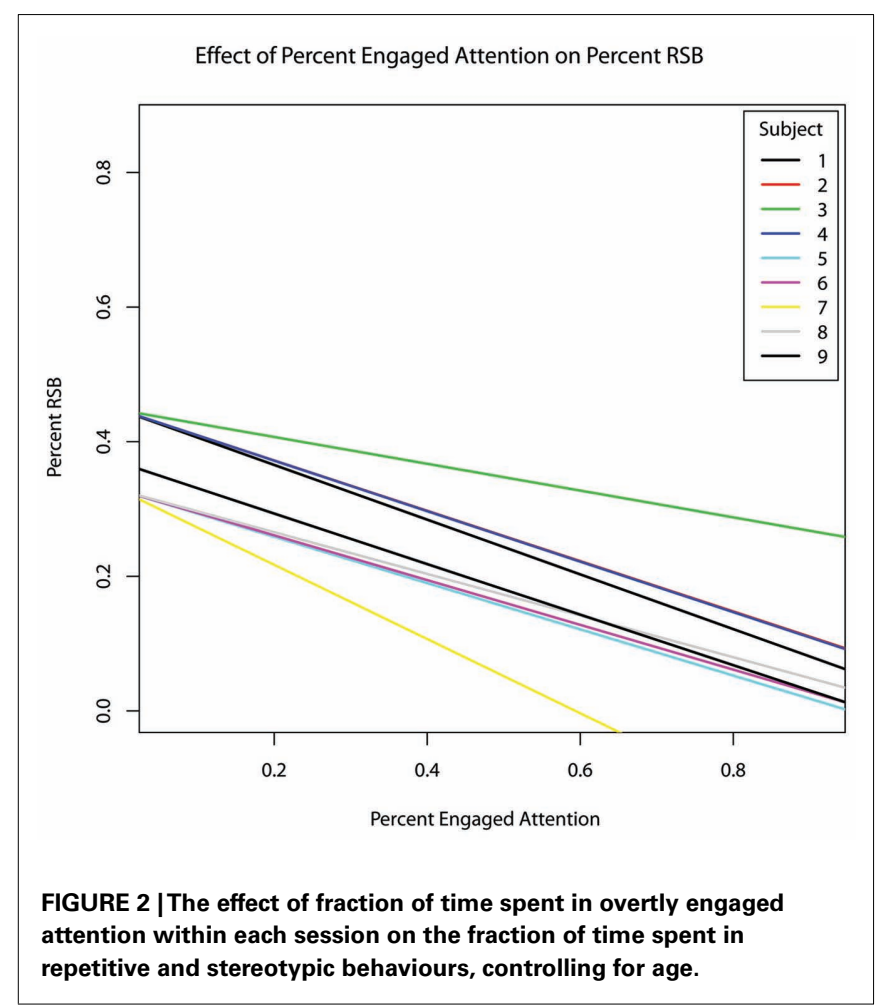

significantly predicted by any specific type of prompt. The rate of distal prompts was a positive, though non-significant predictor of RSB rate $(b=0.2169, p=0.0721)$. No other type of prompt significantly predicted RSB incidence rate. Subjects' response rates and subjects' engaged attention were not significantly related to any specific type of therapist prompt ( $p>0.27$ in all cases). 

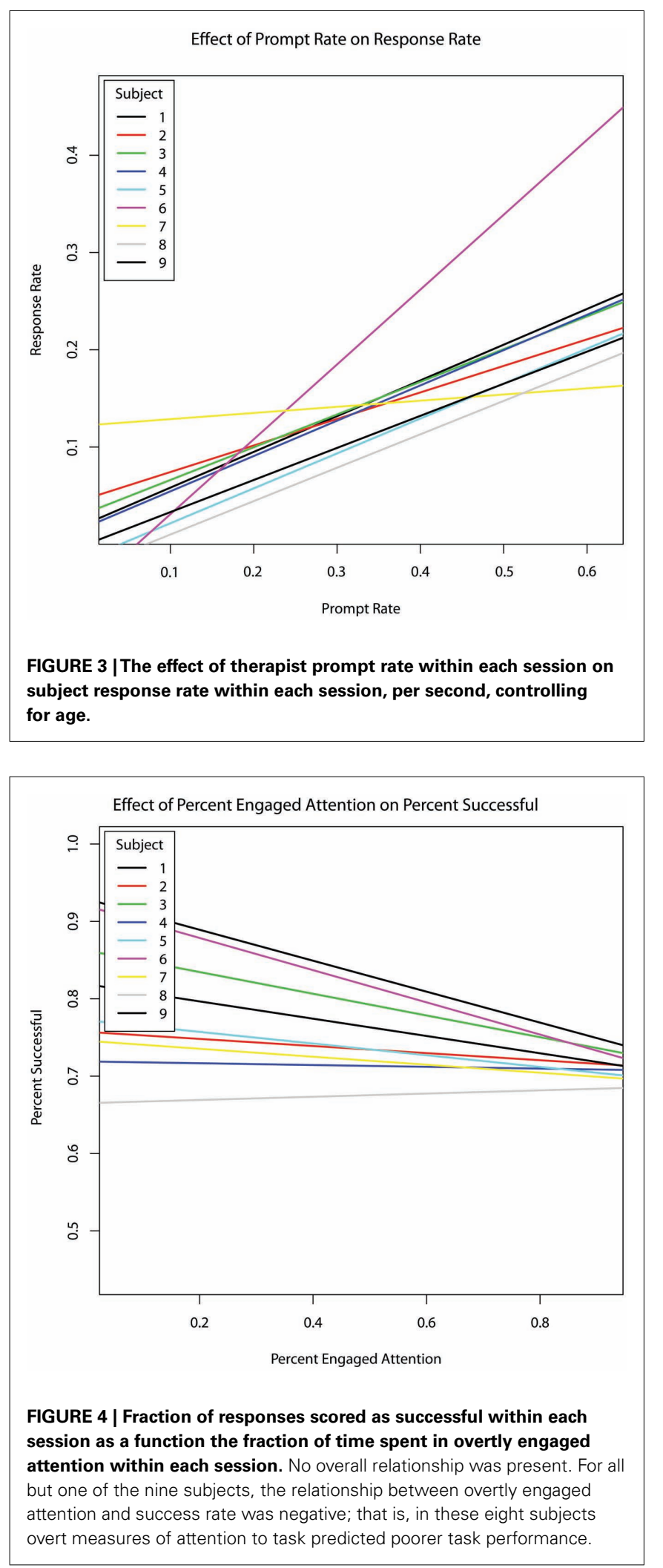

The rate at which the therapist provided proximal prompting trended toward a negative relationship with successful responding $(b=-0.7773, p=0.1034)$. The percentage of

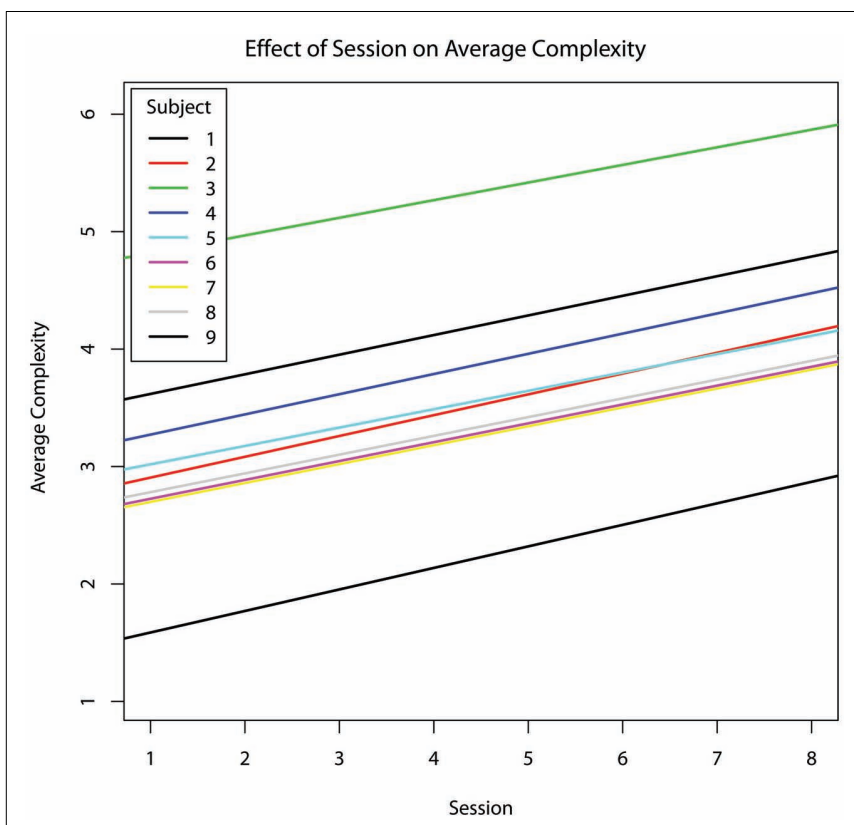

FIGURE 5 |The effect of chronological session on average choice complexity within each session, controlling for age. Choice complexity increased across sessions for every subject (with no decrement in response accuracy).

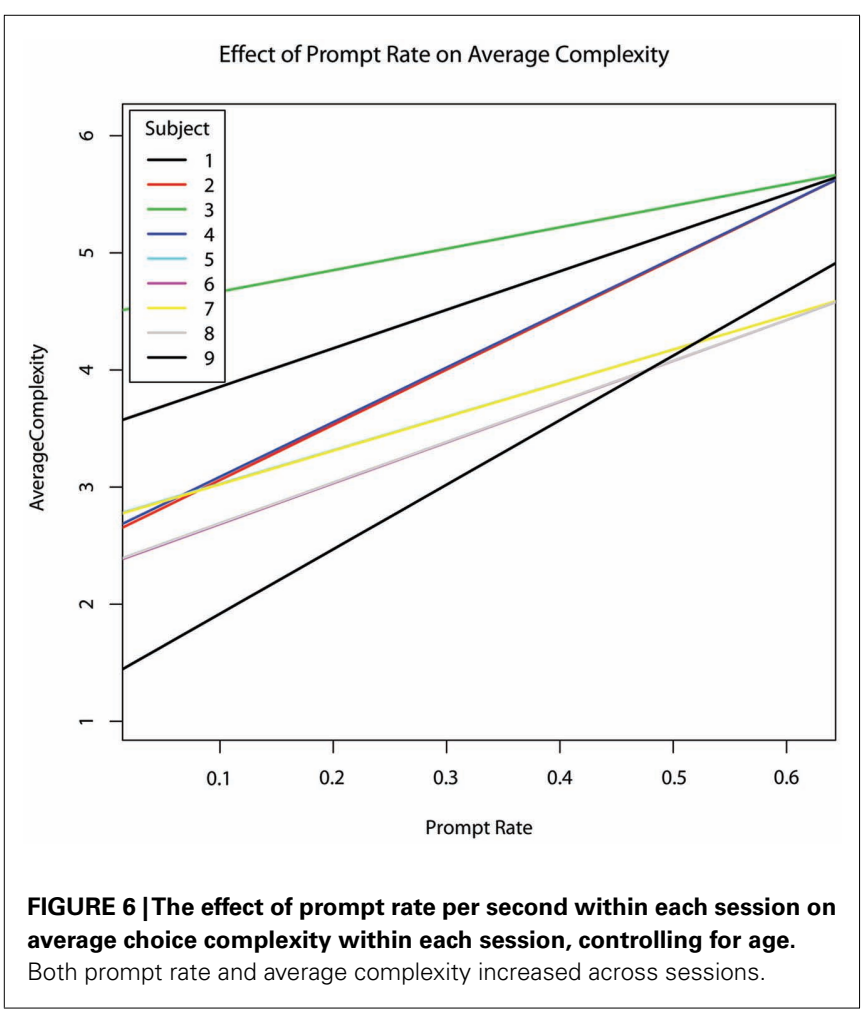

time during which the therapist provided proximal prompting was negatively related to choice complexity $(b=-16.73$, $p=0.0193)$. No other type of therapist prompting was 
Table 8 | Effects of prompting.

\begin{tabular}{|c|c|c|c|c|}
\hline & Distal prompt rate & Proximal prompt rate & Percent distal prompting & Percent proximal prompting \\
\hline Percent engaged & -0.08192 & -0.7413 & -0.1455 & -1.404 \\
\hline Response rate & -0.1510 & -0.2871 & 0.02337 & -0.8368 \\
\hline Percent RSB & -0.3985 & -0.5643 & 0.1733 & 1.787 \\
\hline RSB rate & 0.2169 & -0.1786 & 0.03457 & 0.007196 \\
\hline Percent successful ${ }^{a}$ & -0.2125 & -0.7773 & -0.04477 & -0.8579 \\
\hline Choice complexity & 2.172 & 0.8875 & 0.2464 & $-16.73^{*}$ \\
\hline
\end{tabular}

Rates are defined as the number of occurrences per second. Percents are the percentage of the session during which the specified behaviour was occurring.

${ }^{a}$ Percent Successful is defined as the percentage of responses that were coded as successful.

$R S B$, repetitive and stereotypic behaviour; ${ }^{*} p<0.05$; see text for more precise tail probabilities.

significantly related to successful responding or choice complexity.

Session was not a significant predictor of any type of prompting.

\section{DISCUSSION}

Before discussing the above analysis, it is important to emphasise the exploratory nature of this study. Our results represent a detailed analysis of a small group of subjects undergoing a novel communication therapy. While parametric tests did find statistically significant relationships, individual subjects varied a great deal and the regression line did not always close in on data points from every subject. Future, larger-scale studies can explore and exploit this variation so as to characterise subtypes of individuals in whom the effects and effectiveness of this therapy may differ.

Contrary to our first hypothesis, overt (i.e., gaze) indices of engaged attention did not increase with session order. Interestingly, overtly engaged attention was also not associated with response success (Table 6). In fact, in all but one of the subjects, the correlation between overtly engaged attention (direct gaze) and success was negative (see Figure 4). Because gaze was used as a measure of engaged attention, our data suggest that in some autistic individuals in our sample, direct gaze may actually inhibit the ability to respond correctly. This negative relation between direct gaze and task performance aligns with previous work in autism showing hyperactivation of the amygdala in conjunction with direct gaze at faces, along with a pattern of gaze aversion (Dalton et al., 2005), and with previous research into visuo-proprioceptive integration: people with autism do not integrate visual and proprioceptive inputs as efficiently or as rapidly as people without autism, and therefore do as well or even better when they depend solely on one or the other sensory modality, or when they can prepare movements "offline" on the basis of static visual input rather than dynamic visual feedback (Glazebrook et al., 2009; Haswell et al., 2009). Likewise, people with autism have difficulty integrating simultaneous inputs from distinct perceptual channels (Bertone et al., 2005; Bonneh et al., 2008; Saron et al., 2009; Belmonte et al., 2010). These cognitive and behavioural deficits in simultaneous, integrative "online" processing are consistent with a neurophysiologically based model of autism in which perturbations of neural connectivity degrade the ability to rapidly and flexibly reconfigure cognitive resources to meet changing task demands (Minshew et al., 1997; Belmonte et al., 2004a,b; Gepner and Féron, 2009). Analogously to such difficulties in perceptual or sensorimotor integration, the current result may reflect a difficulty in integrating exogenous sensory input with endogenous cognitive operations - that is, in a disconnected brain in which only one perceptual or cognitive process can have access to the central executive at any one time (Belmonte et al., 2004a), the highly salient, attention-capturing visual input produced by direct gaze might actually distract from the internal cognitive deliberations necessary for correct responding. Looking away from an attended object or person might then develop as an adaptive strategy that permits cognitive processing to proceed. More direct measurement of gaze-related arousal could be examined in future studies, e.g., via recording of skin conductance.

Gaze may not be the only (or even the best) index of engaged attention (Akhtar and Gernsbacher, 2008). Gaze behaviour itself may not be an infallible indication of engaged attention; gazefollowing may occur without shared attention (Leekam et al., 1998). Conversely, engaged attention can be manifest in other observable behaviours (Mundy et al., 1990; Lord et al., 2000), which this coding scheme omits. Cues such as pointing, vocalising, or touching an object may be suitable indicators of joint attention (Gernsbacher et al., 2008), and these alternatives could be less distracting and less demanding of cognitive control and integration than gaze, as they are more dependent on the individual's own motor output than on visual input from an independently changing environment. Haswell et al. (2009) speculate that visual input may be physiologically more difficult to integrate with motor actions than are tactile and proprioceptive inputs, as it depends on the longest-range functional connections. This study did not include automated eye-tracking; instead, gaze direction was determined via video-recorded observations. Future studies could evaluate whether attention to the therapist is indeed unrelated to success rate, whilst attention to objects may be more conducive to eliciting a response.

If this model accurately describes our subjects, gaze toward the therapist in the sessions we observed might not be necessary for successful responses. Receptive language - the understanding of speech - might be highly developed, and productive language might simply be latent and waiting for an appropriate communication method to allow for reciprocal expression (Mundy et al., 2003; 
Gernsbacher et al., 2008). In this study, subjects were observed to be looking at the walls or engaging in RSBs but still appeared to be able to process therapist requests. We expected gaze to be significantly correlated with correctness, yet our results suggest that direct gaze might not have been essential to successful communication across all contexts and all individuals and in our sample.

In support of our second hypothesis, RSBs decreased as therapy progressed (see Figure 1), and decreased as engaged attention increased (see Figure 2). These results indicate that time spent in RPM therapy might reduce the percentage of time that subjects spend exhibiting RSBs. Previous studies of typically developing children have found that compulsive-like rituals and behaviours provide these children with a sense of control over fears and their emotional state of being (Rothbaum and Weisz, 1989; Leonard et al., 1990; Evans et al., 1997, 1999). These studies show that ritualistic behaviours may be adaptive responses to anxiety; in the autism context, we propose that RSBs may serve a similar, anxiety-reducing function, at least in a subgroup of cases - particularly when these subjects begin the therapy. Future studies could confirm this potential relationship via direct measures of autonomic nervous system (ANS) function (e.g., Goodwin et al., 2006). During the initial sessions, subjects are not only unable to communicate, but are also in an unfamiliar environment. As therapy progresses, the therapy environment becomes more familiar. Additionally, subjects' growing ability to respond to increasingly complicated requests from the therapist offers a sense of achievement. More importantly, the therapy ultimately gives the appearance - and perhaps the substance- of a sophisticated means of communication. It would seem likely, especially for persons viewed by many as "non-communicative," that such increased recognition of expressive ability would be immensely rewarding. Thus, one possible explanation may be that subjects' need for expression in the form of repetitive behaviours is obviated by a sense of agency. Similarly, increased cognitive stimulation from the therapy could reduce the need for RSBs.

Contrary to our third hypothesis, therapist prompting was not significantly related to decreases in RSBs (Table 8). In fact, the incidence rate of distal prompts seemed associated with increased RSBs, though the effect did not reach significance $(p=0.0721)$. One possible explanation is that momentary proximal prompts may provide an optimal amount of stimulation which can substitute for RSBs, whereas frequent or long-lasting RSBs may cue the therapist to administer extended prompting. RSBs were found to be unrelated to success rate; this independence of RSBs and successful responding leaves open the possibilities that RSBs might not affect the ability to complete the types of tasks that RPM demands, or that the therapist's student-centred adaptations such as prompting (which was significantly related both to RSBs and to success rate) or adjustments of choice complexity may have suppressed a true relationship between RSBs and success rate. Future research could address these alternative hypotheses.

In partial support of our fourth hypothesis, average choice complexity increased as therapy progressed (Figure 5), although this effect remained at trend level after correction for multiple comparisons. This relationship reflects the transition from two choices (pieces of paper) to as many as 26 choices (full letter board). Though response success did not improve over time, it also did not decline, suggesting that the therapist accurately adapted the complexity of her requests to the level of each subject. This increased task complexity with sustained accuracy, if confirmed in a larger study, would be consistent with RPM's therapeutic claim. A broader range of people with autism may be capable of complex tasks such as those used in RPM - and not merely tasks that are considered low-level rote memory or perception tasks (Dawson et al., 2007). People with autism have been reported to perform superiorly on the Raven's Progressive Matrices, perhaps due to preferential recruitment of perceptually driven occipital more than the centrally connected prefrontal cortices, relative to typically developing controls (Soulières et al., 2009). These studies provide evidence that those with autism may have highly developed, yet latent, intellectual abilities that are not tapped by many experimental paradigms.

A further important question for future research is which aspects of RPM are most related to changes in behaviour. The current study examined therapist prompts. As therapy progressed, the therapist provided more prompting, particularly distal prompting (Table 7), which was related to increased subject responding (Figure 3). At the same time, subjects were presented with choices of greater average complexity (Table 6; Figure 5). Despite the increase in choice complexity, subjects did not show a decrease in the percentage of successful responses. However, response rate was co-linear with average complexity and prompt rate. Thus, this study cannot address whether complexity, prompting, or familiarity with the therapy are more related to increases in subject responding. Future studies could help elucidate these distinctions by changing complexity without a corresponding change in prompting, or vice versa.

Data from this preliminary, exploratory study showed a direct, positive relationship between prompting and response rate, and suggest an increased response sophistication without decreased success. Prompts from the therapist may scaffold a child's attempts at interactive responding. For tactile prompts in particular, previous case studies provide some support for the efficacy of such prompting to support learning (Taylor and Levin, 1998; Shabani et al., 2002; Anson et al., 2008). Additionally, infant studies have shown that body movements can facilitate attentional shifting, helping to redirect attention onto a new object of interest (Robertson et al., 2001, 2007). Although various forms of prompting were coded, no single style of prompting proved effective at scaffolding successful responses across all subjects in our sample. By employing multi-modal prompts, RPM may accommodate a wide range of individual learning styles and modality preferences.

The current study demonstrates RPM's suppressive effect on RSBs that may interfere with learning, and its maintenance of correct responding with increased choice complexity that may support learning - effects that seem to arise as repetitive behaviours are supplanted by prompted, directed behaviours. It also shows no positive relationship and in many individual cases, a negative relationship between direct gaze and correct responding - a result that, though counterintuitive, may not be entirely unexpected given the frequency of anecdotal reports of task-related gaze aversion in autism, and one which recently has garnered specific experimental support from a study showing a lack of integration 
of visual and proprioceptive inputs (Haswell et al., 2009). These results suggest an extension of connectivity-based deficits in complex information processing from the high-functioning autistic population to the non-speaking autistic population. The current study includes a small and heterogeneous set of subjects, and addresses effects of exposure to RPM without testing the validity of the communications elicited by RPM. Nevertheless, the findings are suggestive and set the backdrop for future, prospective studies that can explicitly test the validity of RPM as a method of communication and a vehicle for instruction in minimally speaking individuals with autism for whom few validated therapies have been developed and shown efficacious.

Lastly, it seems worth noting that many aspects of RPM can be construed to differ from typical cognitive strategies in degree though not necessarily in kind. It is normal to fidget as a way of calming oneself, to suppress sensory input by averting gaze when asked to think deeply or in general to exercise a great degree of cognitive control, and in the case of the broader autism phenotype, to have an easier time with social communication via asynchronous

\section{REFERENCES}

Akhtar, N., and Gernsbacher, M. A. (2008). On privileging the role of gaze in infant social cognition. Child Dev. Perspect. 2, 59-65.

Allen, G., and Courchesne, E. (2001). Attention function and dysfunction in autism. Front. Biosci. 6, D105D119.

Anson, H. M., Todd, J. T., and Cassaretto, K. J. (2008). Replacing overt verbal and gestural prompts with unobtrusive covert tactile prompting for students with autism. Behav. Res. Methods 40, 1106-1110.

Arias, P., and Cudeiro, J. (2008). Effects of rhythmic sensory stimulation (auditory, visual) on gait in Parkinson's disease patients. Exp. Brain Res. 186, 589-601.

Baer, D. M., Peterson, R. F., and Sherman, J. A. (1967). The development of imitation by reinforcing behavioral similarity to a model. J. Exp. Anal. Behav. 10, 405-416.

Bakeman, R., and Adamson, L. B. (1984). Coordinating attention to people and objects in mother-infant and peer-infant interaction. Child Dev. 55, 1278-1289.

Baranek, G. T. (1999). Autism during infancy: a retrospective video analysis of sensory-motor and social behaviors at 9-12 months of age. J. Autism Dev. Disord. 29, 213-223.

Baron-Cohen, S. (1989). Joint attention deficits in autism: towards a cognitive analysis. Dev. Psychopathol. 3, 185-190.

Baron-Cohen, S., Cox, A., Baird, G., Swettenham, J., Nightingale, N., Morgan, K., Drew, A., and Charman,
T. (1996). Screening for autism in a large population at 18 months of age: an investigation of the CHAT (checklist for autism in toddlers). Br. J. Psychiatry 168, 158-163.

Belmonte, M. K. (2000). Abnormal attention in autism shown by steady-state visual evoked potentials. Autism 4, 269-285.

Belmonte, M. K., Allen, G., BeckelMitchener, A., Boulanger, L. M., Carper, R. A., and Webb, S. J. (2004a). Autism and abnormal development of brain connectivity. J. Neurosci. 24, 9228-9231.

Belmonte, M. K., Cook, E. H. Jr., Anderson, G. M., Rubenstein, J. L. R., Greenough, W. T., Beckel-Mitchener, A., Powell, S. B., Levitt, P. R., Perry, E. K., Jiang, Y., DeLorey, T. M., and Tierney, E. (2004b). Autism as a disorder of neural information processing: directions for research and targets for therapy. Mol. Psychiatry 9, 646-663.

Belmonte, M. K., Gomot, M., and Baron-Cohen, S. (2010). Visual attention in autism families: 'unaffected' sibs share atypical frontal activation. J. Child Psychol. Psychiatry 51, 259-276.

Belmonte, M. K., and Yurgelun-Todd, D. A. (2003). Functional anatomy of impaired selective attention and compensatory processing in autism. Cogn. Brain Res. 17, 651-664.

Bertone, A., Mottron, L., Jelenic, P., and Faubert, J. (2005). Enhanced and diminished visuo-spatial information processing in autism depends on stimulus complexity. Brain 128, 2430-2341. Courchesne, E., Boulanger, L. M.,

media (e.g., Internet chat) than via real-time social give-and-take (e.g., a conversation at a party). In this regard, examining communicative functions and strategies in autism can tell us a great deal about how to adapt communication to a broad range of normal and abnormal individuals.

\section{ACKNOWLEDGMENTS}

This publication was supported by an agreement with Cornell University, Department of Human Development under Faculty Early Career Development Award BCS-0846892 from the Directorate for Social, Behavioral and Economic Sciences, US National Science Foundation. Matthew Kenneth Belmonte conceived the study; Grace Megumi Chen and Keith Jonathon Yoder with Matthew S. Goodwin and Matthew Kenneth Belmonte designed the study; Grace Megumi Chen and Keith Jonathon Yoder coded the data; Keith Jonathon Yoder with Barbara Lynn Ganzel and Matthew Kenneth Belmonte implemented the statistical analyses; Grace Megumi Chen, Keith Jonathon Yoder, Matthew Kenneth Belmonte, Barbara Lynn Ganzel, and Matthew S. Goodwin wrote the paper.

Bonneh, Y. S., Belmonte, M. K., Pei, F. Iversen, P. E., Kenet, T., Akshoomoff, N. A., Adini, Y., Simon, H. J., Moore, C. I., Houde, J. F., and Merzenich, M. M. (2008). Cross-modal extinction in a boy with severely autistic behaviour and high verbal intelligence. Cogn. Neuropsychol. 25, 635-652.

Boyd, B. A., Baranek, G. T., Sideris, J., Poe, M. D., Watson, L. R., Patten, E., and Miller, H. (2010). Sensory features and repetitive behaviors in children with autism and developmental delays. Autism Res. 3, 78-87.

Bruner, J. S. (1975). From communication to language: a psychological perspective. Cognition 3, 255-287.

Charman, T. (2000). "Theory of mind and the early diagnosis of autism," in Understanding Other Minds: Perspectives from Autism and Developmental Cognitive Neuroscience, eds S. BaronCohen, H. Tager-Flusberg, and D. Cohen (Oxford: Oxford University Press), 422-441.

Charman, T. (2003). Why is joint attention a pivotal skill in autism? Philos. Trans. R. Soc. Lond. B Biol. Sci. 358, 315-324.

Chein, J. M., and Schneider, W. (2005) Neuroimaging studies of practicerelated change: fMRI and metaanalytic evidence of a domaingeneral control network for learning. Cogn. Brain Res. 25, 607-623.

Dadds, M., Schwartz, S., Adams, T., and Rose, S. (1988). The effects of social context and verbal skill on the stereotypic and taskinvolved behaviour of autistic children. J. Child Psychol. Psychiatry 29, 669-676.
Dalton, K. M., Nacewicz, B. M., Johnstone, T., Schaefer, H. S., Gernsbacher, M. A., and Goldsmith, H. H. (2005). Gaze-fixation and the neural circuitry of face processing in autism. Nat. Neurosci. 8, 519-526.

Dawson, M., Soulières, I., Gernsbacher, A., and Mottron, L. (2007). The level and nature of autistic intelligence. Psychol. Sci. 18, 657-662.

Evans, D. W., Gray, F. L., and Leckman, J. F. (1999). Rituals, fears, and phobias of young children: insights from development, psychopathology, and neurobiology. Child Psychiatry Hum. Dev. 29, 261-276.

Evans, D. W., Leckman, J. F., Carter, A., Reznick, J. S., Henshaw, D., King, R. A., and Pauls, D. (1997). Ritual, habit, and perfectionism: the prevalence and development of compulsive-like behavior in normal young children. Child Dev. 68, 58-68.

Forsey, J., Raining Bird, E. K., and Bedrosian, J. (1996). Brief report: the effects of typed and spoken modality combinations on the language performance of adults with autism. J. Autism Dev. Disord. 26, 643-649.

Frith, U., and de Vignemont, F. (2005). Egocentrism, allocentrism, and Asperger syndrome. Conscious. Cogn. 14, 719-738.

Frost, L., and Bondy, A. S. (1994). PECS: The Picture Exchange Communication System Training Manual. Cherry Hill, NY: Pyramid Educational Consultants.

Gepner, B., and Féron, F. (2009). Autism: a world changing too fast for a miswired brain? Neurosci. Biobehav. Rev. 33, 1227-1242. 
Gernsbacher, M. A., Sauer, E. A., Geye, H. M., Schweigert, E. K., and Hill, H. (2008). Infant and toddler oral-and manual-motor skills predict later speech fluency in autism. J. Child Psychol. Psychiatry 49, 43-50.

Glazebrook, C. M., Gonzalez, D., Hansen, S., and Elliot, D. (2009). The role of vision for online control of manual aiming movements in persons with autism spectrum disorders. Autism 13, 411-433.

Goetz, E. M., Holmberg, M. C., and LeBlanc, J. M. (1975). Differential reinforcement of other behavior and noncontingent reinforcement as control procedures during the modification of a preschooler's compliance. J. Appl. Behav. Anal. 8, 77-82.

Goodwin, M. S., Groden, J., Velicer, W. F., Lipsitt, L. P., Baron, M. G., Hofmann, S. G., and Groden, G. (2006). Cardiovascular arousal in individuals with autism. Focus Autism Other Dev. Disabl. 21, 100-123.

Greenspan, S. I. (2001). The affect diathesis hypothesis: the role of emotions in the core deficit in autism and in the development of intelligence and social skills. J. Dev. Learn. Disord. 5, 1-46.

Hagedorn, J., Hailpern, J., and Karahalios, K. G. (2008). "VCode and VData: illustrating a new framework for supporting the video annotation workflow," in Proceedings of the Working Conference on Advanced Visual Interfaces, Napoli, 317-321.

Haswell, C. C., Izawa, J., Dowell, L. R., Mostofsky, S. H., and Shadmehr, R. (2009). Representation of internal models of action in the autistic brain. Nat. Neurosci. 12, 970-972.

Iversen, P. (2007). The Informative Pointing Method. Available at: http://www.StrangeSon.com/ [accessed November 11, 2007].

Karanth, P., Shaista, S., and Srikanth, N. (2010). Efficacy of communication DEALL - an indigenous early intervention program for children with autism spectrum disorders. Indian J. Pediatr. 77, 957-962.

Kasari, C., Paparella, T., Freeman, S., and Jahromi, L. B. (2008). Language outcome in autism: randomized comparison of joint attention and play interventions. J. Consult. Clin. Psychol. 76, 125-137.

Leekam, S. R., Hunnisett, E., and Moore, C. (1998). Target and cues: gazefollowing in children with autism. J. Child Psychol. Psychiatry 39, 951-962.
Leonard, H., Goldberger, E. L., Rapoport, J. L., Cheslow, B. S., and Swedo, S. (1990). Childhood rituals: normal development or obsessive-compulsive symptoms? J. Am. Acad. Child Adolesc. Psychiatry 29, 17-23.

Lord, C., Risi, S., Lambrech, L., Cook, E. H. Jr., Leventhal, B. L., DiLavore, P. C., Pickles, A., and Rutter, M. (2000). The autism diagnostic observation schedule-generic: a standard measure of social and communication deficits associated with the spectrum of autism. J. Autism Dev. Disord. 30, 205-223.

Luiselli, J. K., Myles, E., Evans, T. P., and Boyce, D. A. (1985). Reinforcement control of severe dysfunctional behavior of blind multihandicapped students. Am. J. Ment. Defic. 90, $328-334$.

Minshew, N. J., Goldstein, G., and Siegel, D. J. (1997). Neuropsychologic functioning in autism: profile of a complex information processing disorder. J. Int. Neuropsychol. Soc. 3, 303-316.

Mirenda, P. (2001). Autism, augmentative communication, and assistive technology: what do we really know? Focus Autism Other Dev. Disabl. 16, 141-151.

Mostert, M. P. (2001). Facilitated communication since 1995: a review of published studies. J. Autism Dev. Disord. 31, 287-313.

Mukhopadhyay, S. (2008). Understanding Autism Through Rapid Prompting Method. Denver: Outskirts Press.

Müller, R.-A., Shih, P., Keehn, B., Deyoe, J. R., Leyden, K. M., and Shukla, D. K. (2011). Underconnected, but how? A survey of functional connectivity MRI studies in autism spectrum disorders. Cereb. Cortex 21, 2233-2243.

Mundy, P., Block, J., Delgado, C., Pomares, Y., Van Hecke, A. V., and Parlade, M. V. (2007). Individual differences and the development of joint attention in infancy. Child Dev. 78, 938-954.

Mundy, P., Delgado, C., Block, J., Venezia, M., Hogan, A., and Seibert, J. (2003). A Manual for the Abridged Early Social Communication Scales (ESCS). Coral Gables, FL: Department of Psychology, University of Miami.

Mundy, P., and Sigman, M. (2006). "Joint attention, social competence and developmental psychopathology," in Developmental Psychopathology, Vol. 1. Theory and Methods, 2nd Edn, eds D. Cicchetti and D. Cohen (Hoboken, NJ: Wiley), 293-332.
Mundy, P., Sigman, M., and Kasari, C. (1990). A longitudinal study of joint attention and language development in autistic children. J. Autism Dev. Disord. 20, 115-128.

Nathan, M. J., Eilam, B., and Kim, S. (2007). To disagree, we must also agree: how intersubjectivity structures and perpetuates discourse in a mathematics classroom. J. Learn. Sci. 16, 523-563.

Newson, J., and Newson, E. (1975). Intersubjectivity and the transmission of culture. Bull. Br. Psychol. Soc 28, 437-445.

Osterling, J., and Dawson, G. (1994). Early recognition of children with autism: a study of first birthday home videotapes. J. Autism Dev. Disord. 24, 247-257.

Palomo, R., Belinchon, M., and Ozonoff, S. (2006). Autism and family home movies: a comprehensive review. J. Dev. Behav. Pediatr. 27, 59-67.

Repp, A. C., Deitz, S. M., and Deitz, D. E. (1976). Reducing inappropriate behaviors in classrooms and in individual sessions through DRO schedules of reinforcement. Ment. Retard. 14, 11-15.

Risley, T. R. (1968). The effects and side effects of punishing the autistic behaviors of a deviant child. J. Appl. Behav. Anal. 1, 21-34.

Robertson, S. S., Bacher, L. F., and Huntington, N. L. (2001). The integration of body movement and attention in young infants. Psychol. Sci. 12, 523-526.

Robertson, S. S., Johnson, S. L. Masnick, A. M., and Weiss, S. L. (2007). Robust coupling of body movement and gaze in young infants. Dev. Psychobiol. 49, 208-215.

Rogers, S. J., and Lewis, H. (1989). An effective day treatment model for young children with pervasive developmental disorders. J. Am Acad. Child Adolesc. Psychiatry 28, 207-214.

Roos, E. M, McDuffie, A. S., Weismer, S. E., and Gernsbacher, M. A. (2008). A comparison of contexts for assessing joint attention in toddlers on the autism spectrum. Autism 12, 275-291.

Rothbaum, F., and Weisz, J. (1989). Child Psychopathology and the Quest for Control. Newbury Park, CA: Sage Publications.

Saron, C. D., Beransky, M., Takarae, Y., Horton, D. M., Stark, A., and Rivera, S. M. (2009). Sight, sound and touch less bound: a behavioral and ERP investigation of multisensory integration deficits in children with autism spectrum disorders. Abstracts of the 10th International Multisensory Research Forum, New York, 359.

Schopler, E., Reichler, R. J., DeVellis, R. F., and Daly, K. (1980). Toward objective classification of childhood autism: Childhood Autism Rating Scale (CARS). J. Autism Dev. Disord. 10, 91-103.

Shabani, D. B., Katz, R. C., Wilder, D. A., Beauchamp, K., Taylor, C. R., and Fischer, K. J. (2002). Increasing social initiations in children with autism: effects of a tactile prompt. J. Appl. Behav. Anal. 35, 79-83.

Siller, M., and Sigman, M. (2008). Modeling longitudinal change in the language abilities of children with autism: parent behaviors and child characteristics as predictors of change. Dev. Psychol. 44, 1691-1704.

Smith, V., Mirenda, P., and ZaidmanZait, A. (2007). Predictors of expressive vocabulary growth in children with autism. J. Speech Lang. Hear. Res. 50, 149-160.

Soulières, I., Dawson, M., Samson, F., Barbeau, E. B., Sahyoun, C. P., Strangman, G. E., Zeffiro, T. A., and Mottron, L. (2009). Enhanced visual processing contributes to matrix reasoning in autism. Hum. Brain Mapp. 30, 4082-4107.

Storey, J. D. (2002). A direct approach to false discovery rates. J. $R$. Stat. Soc. 64, 479-498.

Taylor, B. A., and Levin, L. (1998). Teaching a student with autism to make verbal initiations: effects of a tactile prompt. J. Appl. Behav. Anal. 31, 651-654.

Tomasello, M., and Farrar, M. J. (1986). Joint attention and early language. Child Dev. 57, 1454-1463.

Toth, K., Munson, J., Meltzoff, A. N., and Dawson, G. (2006). Early predictors of communication development in young children with autism spectrum disorder: joint attention, imitation, and toy play. J. Autism Dev. Disord. 36, 993-1005.

Watt, N., Wetherby, A., and Shumway, S. (2006). Prelinguistic predictors of language outcome at 3 years of age. J. Speech Lang. Hear. Res. 49, 1224-1237.

Whalen, C., and Schreibman, L. (2003). Joint attention training for children with autism using behavior modification procedures. J. Child Psychol. Psychiatry 44, 456-468.

Whalen, C., Schreibman, L., and Ingersoll, B. (2006). The collateral effects 
of joint attention training on social initiations, positive affect, imitation, and spontaneous speech for young children with autism. J. Autism Dev. Disord. 36, 655-664.

Conflict of Interest Statement: The authors declare that the research was conducted in the absence of any commercial or financial relationships that could be construed as a potential conflict of interest.

Received: 27 August 2011; accepted: 10 January 2012; published online: 16 February 2012.

Citation: Chen GM, Yoder KJ, Ganzel $B L$, Goodwin MS and Belmonte MK
(2012) Harnessing repetitive behaviours to engage attention and learning in a novel therapy for autism: an exploratory analysis. Front. Psychology 3:12. doi: 10.3389/fpsyg.2012. 00012

This article was submitted to Frontiers in Educational Psychology, a specialty of Frontiers in Psychology.
Copyright (C) 2012 Chen, Yoder, Ganzel, Goodwin and Belmonte. This is an openaccess article distributed under the terms of the Creative Commons Attribution Non Commercial License, which permits non-commercial use, distribution, and reproduction in other forums, provided the original authors and source are credited. 